\title{
AN ABNORMALLY LONG STYLOID PROCESS WITH OSSIFICATION OF THE STYLOHYOID LIGAMENT
}

\author{
Guarna $\mathbf{M}^{* 1}$, Aglianò $\mathbf{M}^{1}$. \\ ${ }^{* 1}$ Department of Medical,Surgical Sciences and Neuroscience, University of Siena, Italy. \\ ABSTRACT
}

The styloid process of the temporal bone is an elongated bony projection presenting a variable length as
demonstrated in osteometric and radiological studies conducted with different techniques: three-dimensional
computed tomography (3dct) or dental panoramic three-dimensional scanning. An elongated styloid process
can cause neck pain, dysphagia, headache, sore throat, ear pain, mandibular dysfunction which characterize
Eagle's syndrome. Here we present a rare image of an abnormally long styloid process with ossification of left
stylohyoid ligament belonging to a bone collection of the local anatomical museum, part of our department,
and discovered during routine osteology classes. Also if a direct relation between the length of the styloid
process and syndrome of Eagle is not always obvious, radiologists, neurologists,neurosurgeons, dentists,
anesthetists and otolaryngologists could be aware of this bone anomaly to diagnose this syndrome.
KEY WORDS: Elongated styloid process, Stylohyoid ligament, Ossification, Eagle syndrome.

Address for Correspondence: Massimo Guarna,MD Assistant Professor, Department of MedicalSurgical Sciences and Neuroscience, University of Siena, Italy. E-Mail: guarna@unisi.it

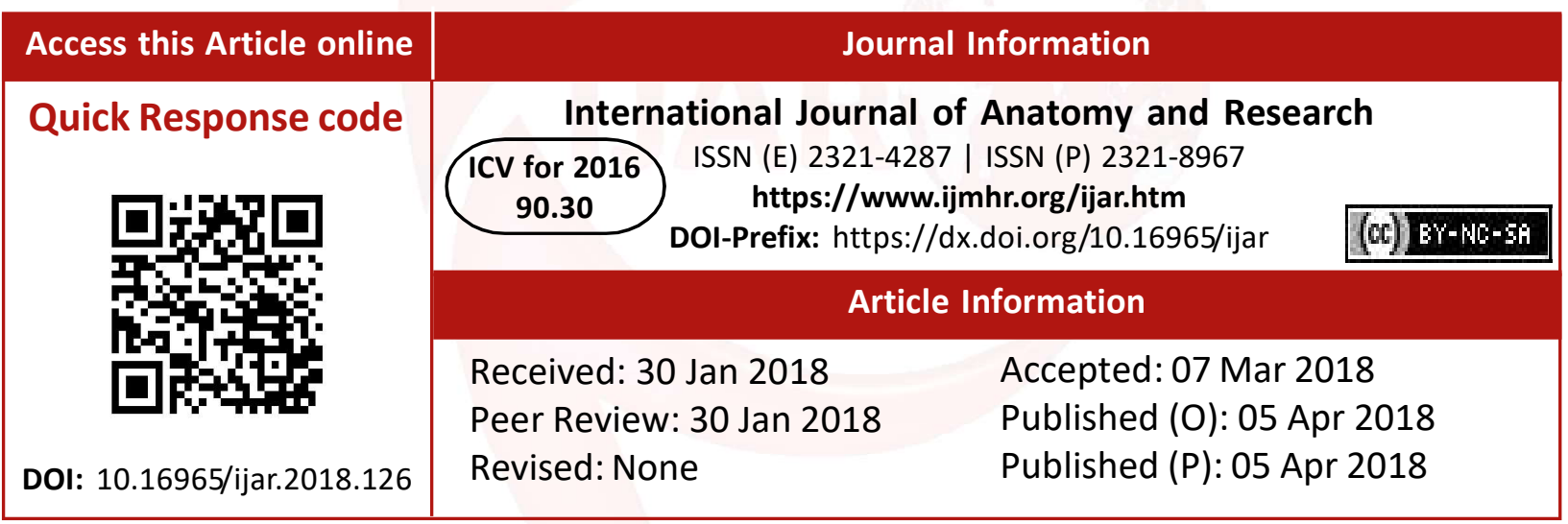

\section{INTRODUCTION}

The styloid process(SP) of the temporal bone has a pointed shape and at the origin of the cranial base is covered by a tympanic bony sheath. In the fetus this process originates from Reichert's cartilage of the second brachial arch. This region of Reichert's cartilage has four separate centers of development: the tympanohyal, the stylohyal, the ceratohyal, and the hypohyal which give origin to different parts of styloid chain.The tympanohyal forms the basis of the (SP).The stylohyal becomes the stem of the SP. The ceratohyal part gives rise to the stylohyoid ligament $(\mathrm{SL})$ and the hypohyal part forms the lesser cornu of the hyoid bone.In rare instances Reichert's cartilage developed into a bar of bone extending from the temporal bone to the hyoid bone [1].
The bone process gives insertion to muscles and ligaments: the stylohyoid and stylomandibular ligaments, as well as the muscles styloglossus, stylospharyngeus, stylohyod [2]. The SL,derived from the ceratohyal part of Reichert's cartilage, extends from the apex of the SP to the tip of the lesser cornu of the hyoid bone. For unknown reason the ligament occasionally ossifies and forms a solid structure. However, the complete ossification is rare.Several studies conducted with different technique reported a variable length for the styloid process. Jung et al [3] with the study of panoramic radiography found an average value of $28 \mathrm{~mm}$ in length and claimed that the SP should be considered to be elongated, when its length was greater than 45 $\mathrm{mm}$. As reported by Patil et al [4], in a recent osteometric study, the mean of length of SP was 
$2.58 \mathrm{~cm}$, and a SP longer than $3 \mathrm{~cm}$ was identified as an elongated SP.

Although partial ossification of the $S L$ is not uncommon, complete ossification is rare. We present the image of a rare anomaly characterized by a temporal bone SP abnormally long with a left ossified SL. The anatomical preparation belonged to a bone collection of the local anatomical museum of Siena "Leonetto Comparini." part of our department.

\section{CASE REPORT}

The SP length was measured using a digital caliper and photographed. The SP was long 50 $\mathrm{mm}$ on the right and $70 \mathrm{~mm}$ on the left (fig 1). The abnormally elongated SP was due to ossification of the SL (fig1). It was attached to the skull base superiorly, just in front of the mastoid process, and inferiorly attached to the hyoid bone.

Fig. 1: Arrow pointing the elongated styloid process and calcified stylohyoid ligament.

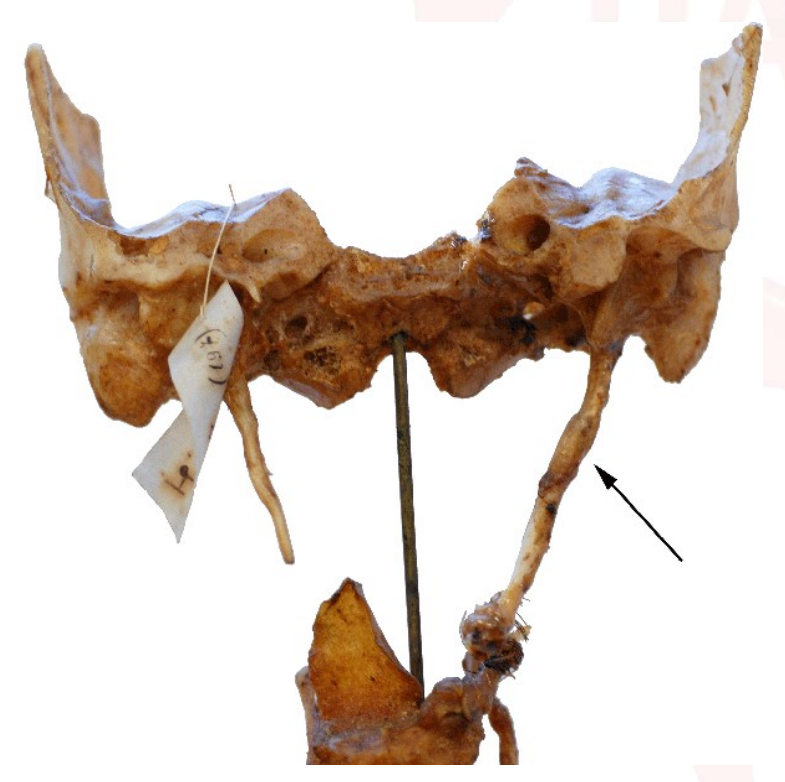

\section{DISCUSSION}

Cases of such a long SP in the dried human skull reported in the literature are quite scant while there are several radiologic studies of this anatomic anomaly. Prabhu et al [5], reported a case of bilateral elongated SP with the length of 60 and $59 \mathrm{~mm}$ on the right and left side, respectively. Paraskevas et al [6] presented a case of the dried skull with an elongated right SP with a length of $58 \mathrm{~mm}$. Ishwar et al [7] reported a bilaterally elongated SP in dried skull measuring $60 \mathrm{~mm}$.
Beder et al.[8] diagnosed SP with the length of $42.5 \mathrm{~mm}$ on the right side and $41.5 \mathrm{~mm}$ on the left side by computed tomography. Using the same imaging technique, Savranlar et al [9] described a case of elongated SP with the length of 45.6. Vougiouklakis reported in an autoptic study [10] that $11 / 1215$ of the cadavers had complete calcification of the SL.Nine out of the eleven cases were bilateral and 2/11 cases show unilateral ossification on the left side. These earlier large series suggest that a fully ossified and abnormally thickened $\mathrm{SL}$ is rare and atypical [11].

Langlais et al [12] recognizes three types of elongated and ossified styloid processes: the first two are interrupted and have pseudo-articulations, the third is an uninterrupted segment formed by the ossified SL. Our case belongs to the third type. Campos et al. [13 ] reported that the etiology of styloid bone elongation can be explained by a genetic alteration or according to several theories.The ossification of the SL could be caused by a pharyngeal trauma which causes metaplastic change. According to the anatomic variance theory, the elongated SP and the ossified SL are anatomical variations that occur without any trauma.

Clinical significance: The abnormal length of SP or the calcification /ossification of SL causing a pressure on neural and vascular structures is sometimes accompanied by a set of symptoms, as neck pain, dysphagia, headache, sore throat, ear pain, mandibular dysfunction which characterize Eagle's syndrome [14].

About $4 \%$ of the population has an elongated SP, but only 4 to $10.3 \%$ of this group has symptoms of this syndrome [15]. Also, if a direct relation between the length of the styloid process and syndrome of Eagle is not always obvious, we can assume that the person with this anomaly may have experienced this syndrome. In the present case, on the left side, we have observed ossification of SL. Diffuse ossification of SL is very rare, and it may remain asymptomatic throughout life.However, especially in older patients it may restrict the neck movements, and difficulty may arise during intubation. An immobile larynx, due to SL ossification would cause difficulties in direct laryngoscopy. 
There might be serious traumatic consequences and possible risk of regurgitation and aspiration especially in emergency situations. Knowledge of the existence of an elongated styloid process and of its possible ossification must be well present to anatomists, radiologists, anesthetists, dentists, neurosurgeons and otolaryngologists.

\section{ABBREVIATIONS}

SP - Styloid Process

SL - Stylohyoid Ligament

\section{Conflicts of Interests: None}

\section{REFERENCES}

[1]. Baugh RF, Stocks RM. Eagle's Syndrome: A reappra isal. Ear Nose Throat J 1993;72:341-344.

[2]. Fini G, Gasparini G, Filippini F, Becelli R , Marcotullio D.The long styloid process syndrome or Eagle's syndrome.Journal of Cranio-Maxillofacial Surgery 2000;28:123-127.

[3]. Jung $T$,Tschernitschek $H$, Hippen $H$, Schneider $B$, Borchers L: Elongated styloid process: when is it really elongated? .Dentomaxillofac Radiol 2004;33(2):119-24.

[4]. Patil S, Ghosh S, Vasudeva N: Morphometric Study of the Styloid Process of Temporal Bone. Journal of Clinical and Diagnostic Research 2014;8(9):4-6.

[5]. Prabhu LV, Kumar A, Nayak SR, Pai MM, Vadgaonkar R, Krishnamurthy A, Madhan Kumar SJ: An unusually lengthy styloid process.Singapore Med J 2007 ;48(2):34-36.

[6]. Paraskevas G K, Raikos A, Lazos LM , Kitsoulis P: Unilateral elongated styloid process: a case report. Cases Journal 2009;2:9135.

[7]. Ishwar B, Gavishiddappa H , Balasaheb P, Balappa B, Ambadasu B :Bilateral elongated styloid process: its anatomical embryological and clinical implications Int J Med Res Health Sci 2013;2(2):273276.
[8]. Beder E, Ozgursoy OB Karatayli Ozgursoy S Anadol :Three-dimensional tomography and surgical treatment for Eagle's syndrome. Ear Nose Throat 2006;85(7):443-5.

[9]. Savranlar A, Uzun L, Uður MB, Ozer T.Three-dimensional CT of Eagle's syndrome. Diagn Interv Radiol 2005;11(4):206-9.

[10]. Vougiouklakis T Overview of the ossified stylohyoid ligament based in more than 1200 forensic autopsies. J Clin Forensic Med 2006;13:268-270.

[11]. Prakash B B, Huban T, Punnose HT. Ossified stylohyoid ligament: A case report. IAIM 2016;3(5):184187.

[12]. Langlais RP, Miles DA, Van Dis ML. Elongated and mineralized styholyoid ligament complex: A proposed classification and report of a case of Eagle's syndrome. Oral Surg Oral Med Oral Pathol 1986;61:527-32.

[13]. Campos D, Silva TH, Kipper JF, Piazza J ,Kraether N. Ossification of styloid ligament and its clinical implication: a report of human cases .J. Morphol. Sci 2011;28(2):137-139.

[14]. Eagle WW. Elongated styloid processes: report of two cases. Arch Otolaryngol 1937;25:584-587.

[15]. Murtagh RD, Caracciolo JT, Fernandez G. CT findings associated with Eagle syndrome. Am J Neuroradiol 2001;22:1401-1402.
How to cite this article:
Guarna M, Aglianò M. AN ABNORMALLY LONG STYLOID PROCESS WITH OSSIFICATION OF THE STYLOHYOID LIGAMENT. Int J Anat Res 2018;6(2.1):5101-5103. DOI: 10.16965/ijar.2018.126

